\title{
A RELIGIÃO E AS ELEIÇÕES MUNICIPAIS BRASILEIRAS DE 2016: A VERDADEIRA NOVIDADE
}

Paul Freston ${ }^{1}$

O texto de Tavares e Oro nos oferece dados extremamente valiosos para mapear e entender a participação religiosa na vida eleitoral brasileira, sobretudo porque o nível municipal é ao mesmo tempo o mais difícil (porque fragmentado) de pesquisar e, em certo sentido, o mais democrático (porque acontece em circunscriçóes eleitorais menores e, portanto, mais acessíveis a uma diversidade maior de candidatos). Evidentemente, os autores nos dão uma fotografia e não dados longitudinais (exceto quando é possível reconstitui-los a partir de outras fontes). Vemos o atleta correndo, mas não vemos se ele está acelerando ou desacelerando, se está correndo com facilidade ou com dificuldade, se controla a corrida ou se apenas reage às iniciativas dos outros corredores.

O texto faz um esforço para incluir todas as confissóes, uma tarefa nada fácil em parte pela amplitude exigida, mas acima de tudo pelos problemas metodológicos que implica. O texto não se delonga numa discussão da dificuldade de definir um candidato "católico" em contraposição a um "evangélico", mas a questão é extremamente complicada, a ponto quase de anular a utilidade da comparação. Por outro lado, o texto reconhece acertadamente que os candidatos católicos assumem atitude militante comparável a dos evangélicos quando ligados de alguma forma ao catolicismo carismático. Essa participação mais explicitamente católica deverá seguir aumentando, mais ou menos na mesma velocidade da diminuição da proporção católica na população. Como sabemos, alguns estados e municípios já têm minorias

1 Professor catedrático em Religião e Política em Contexto Global na Balsillie School of International Affairs, Wilfred Laurier University, Canada, e professor colaborador no Programa de Pós-Graduação em Sociologia da Universidade Federal de São Carlos. Contato: pfreston@gmail.com

Debates do NER, Porto Alegre, Ano i 8, N. 32, P. 8 I-86, JUl./Dez. 20 i 7 
católicas. Mas o grau de explicitação da identidade católica, como de qualquer identidade religiosa, depende não apenas de uma relação inversa com a sua proporção na população, mas também de outros fatores, tais como uma certa "tradição" em cada segmento confessional a respeito do que é considerado "de bom tom" na articulação entre identidade religiosa e candidaturas políticas. Em cada confissão há uma certa inércia tradicionalista nesse sentido, a qual dificulta a consecução das mudanças indicadas pela realidade mutável das relaçóes dentro do campo religioso e em termos da sua imagem na sociedade como um todo.

A predominância carismática nesse tipo de identificação político-religiosa mais "evangélica" faz sentido, pois o catolicismo carismático é por excelência um catolicismo apropriado para um contexto em que a Igreja Católica se encontra cada vez mais como uma denominação entre outras, e não mais como "a Igreja" em sentido único. É um jeito de ser católico, nascido não por acaso nos Estados Unidos onde o catolicismo sempre teve que concorrer num contexto denominacionalista plural. É uma das formas do catolicismo brasileiro se adaptar à nova realidade social e religiosa do país e, embora com certo atraso e remando contra a inércia tradicionalista já mencionada, o estilo carismático de fazer política tenderá a crescer em importância como uma arma cada vez mais potente no arsenal católico extremamente variado de opçóes para exercer a sua influência no campo político. Mas é pouco provável que a hierarquia queira apostar muitas fichas nesse estilo carismático de fazer política, a ponto de deixá-lo tornar-se a forma predominante, como tem acontecido com os evangélicos, porque a hierarquia dispóe de outras armas e resistirá à "tentação" de ser vista como igualada aos evangélicos.

Vemos que os evangélicos controlam 5 das 26 capitais: Rio de Janeiro, Goiânia, Campo Grande, São Luís e Rio Branco. Isso representa um número um pouco abaixo do "esperado" (sete) pela sua porcentagem na população. Eram 22,2\% no censo de 2010 e sabidamente continuam crescendo; foram detectados em 26\% na pesquisa do Pew Fórum de 2014. Claro que a proporção demográfica pode náo ser exatamente a proporção do eleitorado, 
devido à composição etária diferente de cada confissão; mas esta não deve discrepar muito daquela para as religióes maiores. Estes dados, então, nos dão uma base para colocar o desempenho eleitoral de cada confissão dentro de uma certa expectativa realista. Isso se aplica sobretudo aos evangélicos, devido à sua "segunda posição" no campo confessional, portanto minoritária mas ainda em crescimento acelerado, e a natureza da sua vida religiosa, constituída amplamente em congregaçóes e denominaçóes relativamente sólidas. No entanto, é de notar a mudança nesse campo no sentido de uma identidade "evangélica" desdenominacionalizada, já detectada no censo de 2010 e que agora passa a se refletir largamente na prática cada vez mais comum de candidatos se identificarem como genericamente "evangélicos", sem rótulo denominacional. Vinte e cinco dos 154 vereadores eleitos nas 26 capitais estaduais (meus totais diferem um pouco dos autores, mas utilizo os dados deles para cada cidade) são identificados no texto apenas dessa forma. Pode haver várias razóes para isso, inclusive estratégias de maximização do voto evangélico por candidatos evangélicos atuantes que não disponham de base eleitoral suficiente nas suas próprias denominaçóes; ou mesmo a invocaçáo de uma identidade evangélica genérica por evangélicos pouco atuantes que desejem dar mais lastro a suas candidaturas.

A categoria genérica de "evangélico" complica um pouco a análise fascinante dos vereadores eleitos que fazem Tavares e Oro. Mesmo assim, conseguem construir um quadro altamente informativo. Em todas as capitais há vereadores evangélicos, mas o número oscila enormemente, entre apenas 1 em Maceió e Florianópolis, para 13 em Belo Horizonte, 14 em Manaus e 15 em São Paulo. Evidentemente, o tamanho das respectivas Câmaras Municipais influi nesses resultados, mas é digna de nota a quase ausência de vereadores evangélicos em uma capital do Nordeste (tradicionalmente a região mais resistente ao avanço evangélico) e uma do Sul (o qual, nos seus dois estados mais meridionais, constitui hoje o Brasil menos suscetível ao crescimento protestante, uma vez subtraído o efeito da antiga imigração de protestantes históricos europeus, chegando a ser um Brasil mais "Cone Sul” na sua conformação religiosa). Na outra ponta da escala, a presença 
de São Paulo (além do mais, pelo tamanho) e de Manaus (maior representante da Região Norte, a mais evangélica) não surpreendem. Mas, sim, a de Belo Horizonte, refletindo talvez o recente avanço evangélico na outrora resistente Minas Gerais.

A região Nordeste, tradicionalmente resistente ao protestantismo, agora desenvolve um perfil mais diverso: as grandes metrópoles nordestinas começam a parecer mais com o restante do país, mas as capitais menores mudaram menos. Quanto à regiáo Centro-Oeste, os resultados municipais são altamente contraditórios: um retorno relativamente pequeno em vereadores evangélicos, mas os melhores resultados do país nos pleitos majoritários. Em Goiânia, o primeiro e segundo colocados para prefeito são evangélicos; em Campo Grande deu-se o mesmo, sendo que o vice-prefeito eleito também o é.

Aliás, a porcentagem de vereadores evangélicos supera a média de evangélicos na população do município em apenas seis capitais: Palmas, Vitória, Recife, Belo Horizonte, São Paulo e Porto Alegre.

Em termos da composiçáo denominacional dos vereadores evangélicos, a Assembleia de Deus (entende-se, Missão, já que Madureira é contada separadamente) detém uma pluralidade, como seria de esperar, com 42 eleitos nas capitais. Em seguida vem a Universal do Reino de Deus com 30 , resultado que representa um desempenho mais "eficiente", proporcional ao número de membros, do que o da $\mathrm{AD}$. Outros pentecostais somam 26, com destaque para os 5 eleitos da Quadrangular, 4 da Internacional da Graça de Deus e 3 da AD Madureira. Com isso, os claramente pentecostais constituem 98 dos 154 evangélicos eleitos. Mas é possível que outros sejam, já que 25 são definidos apenas como "evangélicos". Os claramente históricos são apenas 31, dos quais 7 adventistas, 5 presbiterianos e 2 luteranos. Mas a força dos históricos depende sobretudo dos 17 vereadores batistas. Mesmo assim, batistas se elegem em apenas dez capitais (quatro em Belo Horizonte), ao passo que assembleianos e universais vencem em 20 capitais cada, mostrando o caráter nacional de sua distribuição.

O texto de Tavares e Oro enfatiza os "partidos cristãos", mas a sua relevância é dúbia. Nenhum deles chega a ser "partido cristão" no sentido 
clássico, sobretudo num contexto partidário extremamente fragmentado e pouco ideológico, e nenhuma grande denominação concentra a sua atuação eleitoral neles.

Quanto à questáo ideológica maior, os autores acertadamente concluem que não se constitui numa variável determinante para obter maior ou menor apoio dos evangélicos. De fato, em Vitória o prefeito de esquerda se reelegeu com o apoio de um senador batista e de alguns partidos cristâos. Em Belém, o segundo colocado para prefeito, pelo PSOL, recebeu apoio de meios evangélicos, principalmente da $\mathrm{AD}$. $\mathrm{E}$ o único prefeito que o PT elegeu em capital estadual em 2016, na cidade de Rio Branco, congrega na Igreja Batista. O quadro brasileiro continua complexo demais para falarmos numa "direita cristâ" que seja determinante no comportamento eleitoral evangélico no Brasil.

Enquanto isso, não resta dúvida em que reside a verdadeira novidade político-religiosa do pleito de 2016: a eleição de Marcelo Crivella para prefeito do Rio de Janeiro. Nunca antes um político pentecostal havia conquistado, pela via eleitoral majoritária, um posto tão importante no Brasil. O corporativismo eleitoral pentecostal, capitaneado desde 1986 pela $\mathrm{AD}$ e pela IURD, por mais bem sucedido que fosse em eleiçóes proporcionais, sempre funcionou como estorvo às aspiraçōes majoritárias, devido à insuficiência de votos evangélicos para vencer eleiçôes para postos executivos em segundo turno e ao alto índice de rejeiçáo geralmente criado pela forte identificação sectária de candidatos pentecostais "oficiais" na vida pública. $\mathrm{O}$ problema havia afligido o próprio Crivella em suas três tentativas anteriores para prefeito ou governador. Em 2016, no entanto, a barreira foi finalmente superada. Sem dúvida, colaborou para isso o crescimento evangélico na populaçáo do Rio de Jeneiro, além do paciente trabalho de "normalização" política da figura de Crivella, já senador há 14 anos, e até de "normalização", ao menos parcial, da presença da IURD na sociedade brasileira (já vai longe o "chute na santa" e outros incidentes). Mas é improvável que tudo isso bastasse em tempos normais. A conjuntura política anormal de 2016, 
pós-impeachment; a ausência de uma forte candidatura peemedebista no pleito carioca; a passagem para o segundo turno, como adversário de Crivella, de um candidato do PSOL - tudo isso contribuiu para debelar a tradicional rejeição a um candidato pentecostal em segundo turno. Quão significativo esse breakthrough eleitoral será no engajamento político pentecostal como um todo, só o tempo dirá.

Recebido em: 07/08/2017

Aprovado em: 07/08/2017 